\title{
Suplementação de lisina e metionina em associação ou não com o óleo de soja na dieta de vacas leiteiras
}

[Supplementation of lysine and methionine in association or not with soybean oil in dairy cow diets]

\author{
H.N. Frota ${ }^{1}$, R.B. Reis ${ }^{2}$, B.N. Faria ${ }^{2}$, S.G. Coelho ${ }^{2}$, H.M. Saturnino ${ }^{2}$ \\ ${ }^{1}$ Aluna de pós-graduação - Escola de Veterinária - Universidade Federal de Minas Gerais - Belo Horizonte, MG \\ ${ }^{2}$ Escola de Veterinária - Universidade Federal de Minas Gerais - Belo Horizonte, MG
}

\begin{abstract}
RESUMO
O objetivo do estudo foi avaliar a suplementação de lisina e metionina em associação ou não ao óleo de soja na dieta de vacas leiteiras e seus efeitos sobre a produção e a composição do leite. Doze vacas Holandesas foram distribuídas em quadrado latino 4x4, com as dietas O+LM (dieta acrescida de óleo de soja, lisina e metionina misturados na dieta total), OLM (dieta com o complexo óleo de soja/lisina e metionina fornecido separadamente da dieta total), OS (dieta acrescida de óleo de soja fornecido separadamente da dieta total) e LM (dieta acrescida de lisina e metionina fornecidos separadamente da dieta total). A produção de leite, a de proteína e a de gordura não foram afetadas pela adição de lisina e metionina associadas ou não com óleo de soja. O percentual de gordura do leite, a produção de leite corrigida para 3,5\% de gordura e a produção de leite corrigida para sólidos totais reduziram-se com a adição de óleo de soja na dieta. O percentual de proteína aumentou $0,14 \%(\mathrm{p} \leq 0,05)$ com a adição de óleo na presença de lisina e metionina na dieta. Os resultados sugerem efeito protetor do complexo óleo/lisina e metionina da degradação ruminal na condição experimental proposta.
\end{abstract}

Palavras-chave: aminoácidos, produção de leite, composição do leite

\begin{abstract}
The aim of this study was to evaluate the effects of lysine and methionine supplementation with or without soybean oil in the diet of dairy cows on milk production and composition. Twelve Holstein cows were randomly distributed in a $4 x 4$ latin square where the diets were $O+L M$ (diet with soybean oil, lysine and methionine added in the total mixed ration), OLM (diet with complex soybean oil/ lysine and methionine provided as top dressed), OS (diet with soybean oil provided as top dressed) and LM (diet with lysine and methionine provided as top dressed). The milk production, milk protein and milk fat production were not affected by the addition of lysine and methionine in association or not with soybean oil in the diet. The milk fat percentage, $3.5 \%$ fat-corrected milk and solids corrected milk were reduced with increasing soybean oil in the diet. The milk protein percentage increased in $0.14 \%(P \leq 0.05)$ when soybean oil was added to the diet in the presence of the lysine and methionine. The results suggest a protection effect of oil/lysine and methionine complex from the rumen degradation in this experimental condition.
\end{abstract}

Keywords: aminoacids, milk production, milk composition

\section{INTRODUÇÃO}

O fornecimento de proteína em quantidade e qualidade adequada na dieta de ruminantes foi, por muito tempo, considerado pouco importante para os nutricionistas, em razão da alta qualidade da proteína sintetizada pelos micro-organismos ruminais. A proteína microbiana é produzida em quantidade suficiente para suprir parte das necessidades proteicas do ruminante. Segundo Virtanen (1966), pesquisas conduzidas nos anos 60 mostraram que o rúmen foi capaz de suprir toda a proteína necessária para a produção de até $4500 \mathrm{~kg}$ de leite/lactação de vacas que receberam ureia como única fonte de nitrogênio.

Recebido em 5 de fevereiro de 2013

Aceito em 16 de dezembro de 2013

E-mail: helenafrota@hotmail.com 
Com o aumento do potencial genético da vaca leiteira, houve necessidade de ajustes no requisito de nutrientes específicos. Assim, a preocupação com a qualidade da proteína não degradável no rúmen e com a respectiva disponibilidade de aminoácidos pós-ruminal foi enfatizada (Broderick et al., 2008).

Lisina e metionina são consideradas os principais aminoácidos limitantes para a produção e a síntese de proteína do leite de vacas de alta produção (National..., 2001).

No entanto, o fornecimento de aminoácidos essenciais em dietas de ruminantes é bastante discutido, já que os micro-organismos presentes no rúmen, retículo e omaso degradam parcialmente os ingredientes da dieta e os reutilizam para seu crescimento. Assim, os nutrientes disponíveis para absorção podem diferir daqueles presentes na dieta, o que não possibilita a simples adição de um aminoácido na dieta ser opção eficiente para aumentar o fluxo de aminoácidos para o duodeno (Lapierre et al., 2006).

Os aminoácidos incorporados à dieta devem, portanto, ser protegidos da degradação ruminal para estarem disponíveis em quantidade e qualidade suficiente no intestino delgado. $\mathrm{O}$ conceito de proteção de proteína da degradação ruminal tem como principal objetivo intensificar o fornecimento de aminoácidos essenciais para a produção animal e reduzir perdas de nitrogênio na urina (Annison, 1981, citado por Kamalak et al., 2005). É possível proteger proteínas por meio de alguns procedimentos, como o tratamento com calor, tratamento/modificação química, inibição da atividade proteolítica e identificação de proteínas naturalmente protegidas. O óleo parece inibir a degradação da proteína no rúmen e, assim, eleva a quantidade de aminoácidos dietéticos para absorção pós- ruminal (Jenkins e Fatouhi, 1990).

O objetivo deste estudo foi avaliar a suplementação de lisina e metionina, em associação ou não com o óleo de soja, na dieta de vacas leiteiras e seus efeitos sobre a produção e composição do leite.

\section{MATERIAL E MÉTODOS}

Foram utilizadas 12 vacas da raça Holandesa, oito multíparas e quatro primíparas, com DEL médio de 100 dias e produção média de leite de 34,7 litros, em delineamento quadrado latino $4 \mathrm{x}$ 4, com períodos experimentais de 21 dias cada (número do protocolo de aprovação do Comitê de Ética: 181/2009).

A composição das dietas experimentais encontrase na Tab. 1.

Tabela 1. Composição das dietas experimentais

\begin{tabular}{|c|c|c|c|c|}
\hline \multirow{2}{*}{ Ingredientes } & \multicolumn{4}{|c|}{ Dietas } \\
\hline & $\mathrm{O}+\mathrm{LM}$ & OLM & OS & LM \\
\hline & \multicolumn{4}{|c|}{$(\% M S)$} \\
\hline Silagem de milho & 49,40 & 49,40 & 49,62 & 48,41 \\
\hline Milho moído & 16,48 & 16,48 & 16,54 & 19,16 \\
\hline Farelo de soja & 21,82 & 21,82 & 21,92 & 21,38 \\
\hline Polpa de citrus & 6,18 & 6,18 & 6,20 & 6,05 \\
\hline Protenose & 1,07 & 1,07 & 1,08 & 1,05 \\
\hline Premix mineral vitamínico ${ }^{1}$ & 2,26 & 2,26 & 2,27 & 2,22 \\
\hline Farelo de trigo & 1,11 & 1,11 & 1,12 & 1,09 \\
\hline Óleo de soja & 1,03 & 1,03 & 1,04 & 0,00 \\
\hline Lisina & 0,45 & 0,45 & 0,00 & 0,44 \\
\hline Metionina & 0,20 & 0,20 & 0,00 & 0,20 \\
\hline Ureia & 0,00 & 0,00 & 0,21 & 0,00 \\
\hline
\end{tabular}

$\mathrm{O}+\mathrm{LM}$ = controle; $\mathrm{OLM}$ = aminoácidos complexados com óleo; $\mathrm{OS}=$ óleo de soja; $\mathrm{LM}$ = aminoácidos.

${ }^{1}$ Premix mineral vitaminico: $16,0 \% \mathrm{Ca} ; 3,2 \% \mathrm{P} ; 10,6 \% \mathrm{Na} ; 2,0 \% \mathrm{~K} ; 1,2 \% \mathrm{~S} ; 5,1 \% \mathrm{Mg} ; 10 \mathrm{ppm} \mathrm{Co} ; 500 \mathrm{ppm} \mathrm{Cu}$ $1580 \mathrm{ppm} \mathrm{Fe} ; 25 \mathrm{ppm} \mathrm{I} ; 1000 \mathrm{ppm} \mathrm{Mn;} 12 \mathrm{ppm} \mathrm{Se} ; 1800 \mathrm{ppm} \mathrm{Zn;} 140.000 \mathrm{mg} / \mathrm{kg}$ vit. A; $38.000 \mathrm{mg} / \mathrm{kg}$ vit. D; $1.000 \mathrm{mg} / \mathrm{kg}$ vit. $\mathrm{E} ; 33 \mathrm{mg} / \mathrm{kg}$ biotina; $500 \mathrm{mg} / \mathrm{kg}$ monensina. 
As dietas experimentais testadas foram: dieta O+LM, constituída pela dieta base acrescida de óleo de soja $(250 \mathrm{~mL})$, lisina $(110 \mathrm{~g} / \mathrm{d})$ e metionina $(50 \mathrm{~g} / \mathrm{d})$ adicionados separadamente e misturados na TMR; dieta OLM, constituída pela dieta base mais o complexo óleo de soja $(250 \mathrm{~mL})$, lisina $(110 \mathrm{~g} / \mathrm{d})$ e metionina $(50 \mathrm{~g} / \mathrm{d})$ fornecidos sobre a dieta total; dieta OS, constituída pela dieta base acrescida de óleo de soja $(250 \mathrm{~mL})$ fornecido sobre a dieta total; dieta LM, constituída pela dieta base acrescida de lisina $(110 \mathrm{~g} / \mathrm{d})$ e metionina $(50 \mathrm{~g} / \mathrm{d})$ fornecidas também sobre a dieta total.

As dietas experimentais foram balanceadas segundo o National... (2001), para serem isoproteicas e isoenergéticas (Tab. 2). A silagem de milho foi o volumoso base utilizado nas dietas experimentais. Os aminoácidos lisina (Ajinomoto) e metionina (Adisseo) não eram protegidos da degradação ruminal e possuíam 99\% de pureza. As quantidades de lisina e metionina fornecidas na dieta foram determinadas a fim de atender a exigência ideal desses aminoácidos no percentual de proteína metabolizável, segundo o National... (2001).

Devido à possibilidade de parte dos aminoácidos fornecidos sofrer ação das bactérias ruminais, foi adicionada à dieta $30 \%$ a mais da quantidade de lisina e metionina. As dietas O+LM e OLM e a dieta LM forneciam, aproximadamente, $107 \mathrm{e}$ $110 \%$ do requerimento de lisina e metionina na proteína metabolizável, respectivamente; e a dieta OS fornecia 75 e $58 \%$ do requisito de lisina e metionina na proteína metabolizável, respectivamente. $\mathrm{O}$ fornecimento de lisina $\mathrm{e}$ metionina foi reajustado diariamente, de acordo com o consumo de matéria seca.

Tabela 2. Composição química das dietas experimentais

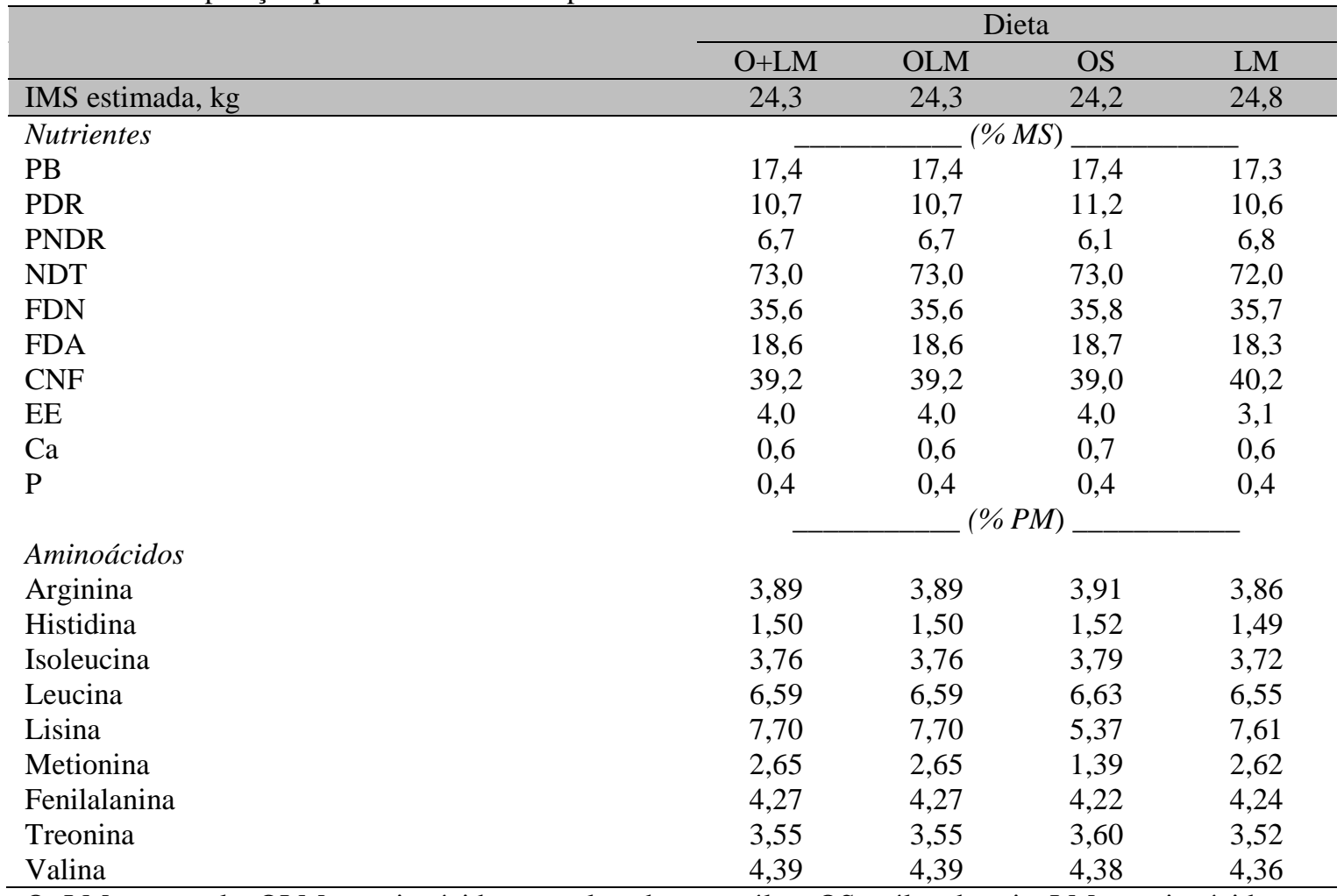

O+LM = controle; OLM = aminoácidos complexados com óleo; OS = óleo de soja; LM = aminoácidos. IMS = ingestão de matéria seca; MS = matéria seca; $\mathrm{PB}=$ proteína bruta; $\mathrm{PDR}$ = proteína degradável no rúmen; PNDR = proteína não degradável no rúmen NDT = nutrientes digestíveis totais; FDN = fibra insolúvel em detergente neutro; FDA = fibra insolúvel em detergente ácido; $\mathrm{CNF}=$ carboidrato não fibroso; $\mathrm{EE}=$ extrato etéreo; $\mathrm{MM}=$ matéria mineral; $\mathrm{Ca}=$ cálcio; $\mathrm{P}=$ fósforo; $\mathrm{PM}=$ proteína metabolizável. 
Os animais foram alimentados em baias individuais, duas vezes ao dia, às 6 h30 e às 17 horas. A dieta foi fornecida na forma de dieta total, permitindo-se sobra de 5 a $10 \%$. O consumo e a sobra foram monitorados e ajustados diariamente.

Os aditivos (óleo e aminoácidos) das dietas OLM, OS e LM foram fornecidos na alimentação da manhã separados da dieta total (Top dressed). Entretanto, na dieta $\mathrm{O}+\mathrm{LM}$ foram misturados à dieta total e fornecidos também na alimentação da manhã.

A ordenha dos animais foi realizada duas vezes ao dia, às seis horas e às 16 h30. Imediatamente após a ordenha, os animais foram conduzidos para as baias de alimentação, onde permaneceram por três horas, e, em seguida, soltos na área de descanso. Todos os animais tiveram livre acesso à água e receberam suplementação mineral.

A produção de leite foi determinada durante o $15^{\circ}$ e $16^{\circ}$ dias do período experimental, em quatro ordenhas consecutivas, que foram amostradas para determinação da proteína, da gordura, da lactose, da contagem de células somáticas (CCS), do extrato seco total e desengordurado. As amostras de leite foram acondicionadas em frascos com 2-bromo 2nitropropano 1,3-diol, na relação de $10 \mathrm{mg}$ para $50 \mathrm{~mL}$ de leite, e foram enviadas para análise, sob refrigeração $\left(4^{\circ} \mathrm{C}\right)$, ao Laboratório de Análise da Qualidade do Leite da Escola de Veterinária da UFMG (LabUFMG) (ChemSpeck 150 de espectrofotometria de transreflectância).

Após as análises, a produção de leite foi corrigida para 3,5\% de gordura ( $\boldsymbol{L} \boldsymbol{C G} \mathbf{3}, 5 \%$ ), sendo obtida pela equação citada por Gravert (1987): $\boldsymbol{L C G} \mathbf{3 , 5 \%}=(0,35 \times \mathrm{PL})+(16,2 \times \mathrm{PG})$, sendo: $\mathrm{PL}=$ produção de leite $(\mathrm{kg} / \mathrm{dia})$ e $\mathrm{PG}=$ produção de gordura (kg/dia).

A produção de leite corrigida para sólidos totais (LCST) foi calculada segundo a equação descrita por Tyrrel e Reid (1965): $\boldsymbol{L C S T}=(12,3 \times \mathrm{PG})+$ $(6,56 \times \mathrm{ESD})-(0,0752 \times \mathrm{PL})$, sendo: $\mathrm{PG}=$ produção de gordura $(\mathrm{kg} / \mathrm{dia}) ; \mathrm{ESD}=$ produção de extrato seco desengordurado e $\mathrm{PL}=$ produção de leite $(\mathrm{kg} / \mathrm{dia})$.
A determinação da matéria seca da dieta foi realizada em estufa a $105^{\circ} \mathrm{C}$, por cinco horas, para determinação da matéria seca total. Os teores de cinzas, matéria orgânica e extrato etéreo foram determinados segundo a AOAC (Association..., 1997).

A proteína bruta foi analisada pelo método de Kjedhall (Association..., 1997). A análise de FDN e FDA foi realizada em aparelho ANKON® Fiber Analyser (ANKON Technology Corporation, Fairport, EUA) de acordo com o método proposto por Van Soest et al. (1991). A porcentagem de carboidratos não fibrosos foi calculada utilizando-se a equação proposta pelo NRC (National..., 2001).

As variáveis testadas foram analisadas pelo programa PROC GLM do programa estatístico SAS (Statistical..., 1999).

Para os testes dos fatores de interesse, foram realizados os contrastes: LIPÍDEO = compara a média da dieta O+LM e OLM com a média da dieta LM para testar o efeito do óleo na presença de lisina e metionina; $\mathrm{AA}=$ compara a média da dieta O+LM e OLM com a média da dieta OS para testar o efeito da lisina e metionina na presença de óleo; e LIPxAA = compara a média da dieta OS com a média da dieta LM, para, assim, comparar o efeito do óleo com o efeito da lisina e metionina.

\section{RESULTADOS E DISCUSSÃO}

As médias de produção de leite das dietas O+LM; OLM; OS e LM foram, respectivamente, 32,$1 ; 31,7 ; 31,7$ e $32,9 \mathrm{~kg}$ de leite/dia. Os contrastes para pesquisa dos efeitos de lipídeos, aminoácidos e interação lipídeo $\mathrm{x}$ AA não apresentaram diferença significativa para os valores de produção de leite (Tab. 3).

$\mathrm{O}$ aumento na produção de leite em resposta à suplementação com aminoácidos protegidos geralmente é limitado a vacas no início da lactação, uma vez que estas necessitam de maior quantidade de aminoácidos absorvíveis (Polan et al., 1991; Schwab et al., 1992). No presente estudo, a adição de óleo, de lisina e de metionina ou a associação de lipídeo com os aminoácidos não afetou a produção de leite $(p \geq 0,05)$, sugerindo que não houve deficiência em aminoácidos essenciais ou que os aminoácidos 
metionina e lisina não foram limitantes para este nível de produção e/ou fase de lactação. Dessa forma, tornou-se difícil a avaliação da proteção dos aminoácidos com o óleo, uma vez que pode não ter ocorrido deficiência dos aminoácidos e a maior disponibilidade de aminoácidos limitantes para serem absorvidos no intestino delgado não promoveu mais estímulo para glândula mamária.

Tabela 3. Produção e composição do leite de vacas em dietas suplementadas com lisina e metionina associadas ou não com óleo de soja

\begin{tabular}{|c|c|c|c|c|c|c|c|c|}
\hline \multirow[b]{2}{*}{ Variável } & \multicolumn{4}{|c|}{ Dietas } & \multirow{2}{*}{ EPM } & \multicolumn{3}{|c|}{ Estimativas dos contrastes } \\
\hline & $\mathrm{O}+\mathrm{LM}$ & OLM & OS & LM & & LIPÍDEO & AA & LIPxAA \\
\hline $\begin{array}{l}\text { Prod. leite, } \\
\text { kg/dia }\end{array}$ & 32,1 & 31,7 & 31,7 & 32,9 & 0,63 & $-1,0$ & 0,2 & $-1,2$ \\
\hline $\begin{array}{l}\text { LCG 3,5\%, } \\
\mathrm{kg} / \mathrm{dia}\end{array}$ & 25,3 & 25,0 & 26,6 & 29,0 & 0,59 & $-3,9 * * *$ & $-1,5 * *$ & $-2,4 * * *$ \\
\hline LCST, $\mathrm{kg} / \mathrm{dia}$ & 26,9 & 26,5 & 27,8 & 29,9 & 0,58 & $-3,2 * * *$ & $-1,1 *$ & $-2,1 * *$ \\
\hline Gordura, \% & 2,70 & 2,65 & 2,94 & 3,29 & 0,08 & $-0,62 * * *$ & $-0,26 * * *$ & $-0,35 * * *$ \\
\hline $\begin{array}{l}\text { Gordura, } \\
\text { kg/dia }\end{array}$ & 0,93 & 0,87 & 0,91 & 1,06 & 0,09 & $-0,15$ & $-0,01$ & $-0,15$ \\
\hline Proteína, \% & 3,30 & 3,33 & 3,26 & 3,17 & 0,05 & $0,14 * *$ & 0,05 & 0,09 \\
\hline $\begin{array}{l}\text { Proteína, } \\
\text { kg/dia }\end{array}$ & 1,04 & 1,00 & 0,99 & 1,07 & 0,04 & $-0,06$ & 0,03 & $-0,09^{*}$ \\
\hline Lactose, \% & 4,82 & 4,79 & 4,85 & 4,87 & 0,02 & $-0,06 * * *$ & $-0,04^{*}$ & $-0,03$ \\
\hline $\begin{array}{l}\text { Lactose, } \\
\mathrm{kg} / \mathrm{dia}\end{array}$ & 1,56 & 1,48 & 1,49 & 1,63 & 0,07 & $-0,11$ & 0,03 & $-0,14^{*}$ \\
\hline
\end{tabular}

$\mathrm{O}+\mathrm{LM}=$ controle; OLM = aminoácidos complexados com óleo; OS = óleo de soja; LM = lisina e metionina. $\mathrm{LIPÍDEO}=\left(\mathrm{X}^{\mathrm{O}+\mathrm{LM}}+\mathrm{X}^{\mathrm{OLM}}\right) / 2-\mathrm{X}^{\mathrm{LM}} ; \mathrm{AA}=\left(\mathrm{X}^{\mathrm{O}+\mathrm{LM}}+\mathrm{X}^{\mathrm{OLM}}\right) / 2-\mathrm{X}^{\mathrm{OS}} ;$ LIPxAA $=\mathrm{X}^{\mathrm{OS}}-\mathrm{X}^{\mathrm{LM}} ; \mathrm{EPM}=$ erro-padrão da média; LCG 3,5\% = produção de leite corrigida para o teor de gordura de 3,5\%; LCST = produção de leite corrigida para sólidos totais.

* $\mathrm{p} \leq 0,10$.

** $\mathrm{p} \leq 0,05$.

$* * * \mathrm{p} \leq 0,01$.

Os valores de produção de leite corrigida para $3,5 \%$ de gordura e de produção de leite corrigida para sólidos totais também estão descritos na Tab. 3. No contraste LIPÍDEO, que testa o efeito do óleo na presença de lisina e metionina, observa-se que o óleo na presença de aminoácidos reduziu em $3,9 \mathrm{~kg} / \mathrm{dia}(\mathrm{p} \leq 0,01)$ a produção de leite corrigida para gordura. O contraste AA mostra que o aminoácido na presença do óleo também reduziu a produção de leite corrigida para gordura de $1,5 \mathrm{~kg} / \mathrm{dia}$ $(p \leq 0,05)$. No contraste LIPxAA, observa-se que o óleo causou queda na produção de leite corrigida para gordura de $2,4 \mathrm{~kg} / \mathrm{dia} \quad(\mathrm{p} \leq 0,05)$ quando comparado à suplementação com aminoácidos.

O efeito das dietas testadas neste estudo sobre a produção de leite corrigida para 3,5\% de gordura pode estar relacionado também ao efeito da suplementação com óleo, o que diminui a concentração de gordura do leite.
A queda no teor de gordura de leite afetou não somente a produção de leite corrigida para gordura, mas também a produção de leite corrigida para sólidos totais, uma vez que ambas as fórmulas propostas para a correção desses dois valores consideram a produção de gordura.

O óleo na presença de aminoácidos reduziu a produção de leite corrigida para sólidos totais em $3,2 \mathrm{~kg} /$ dia $(\mathrm{p} \leq 0,01)$; a lisina e a metionina na presença do óleo reduziram a produção de leite corrigida para sólidos totais em $1,1 \mathrm{~kg} / \mathrm{dia}$ $(\mathrm{p} \leq 0,10)$, e a presença do óleo em comparação à presença de lisina e metionina reduziu a produção de leite corrigida para sólidos totais em $2,1 \mathrm{~kg} / \mathrm{dia}(\mathrm{p} \leq 0,05)$.

Ainda na Tab. 3 são apresentados os valores da composição do leite. No contraste LIPÍDEO, observa-se que a presença do óleo juntamente com lisina e metionina reduziu o percentual de gordura em 0,62 $(\mathrm{p} \leq 0,01)$. Lisina e metionina na presença de óleo (contraste AA) também 
reduziram o teor de gordura do leite em 0,26 $(p \leq 0,01)$. Quando se compara a suplementação de óleo com a suplementação de lisina e metionina (contraste LIPxAA), nota-se que a presença do óleo reduziu o percentual de gordura em $0,35(p \leq 0,01)$. Esse efeito pode ser explicado pela ação do lipídeo prontamente disponível no rúmen sobre o metabolismo ruminal e a síntese de gordura do leite, ou seja, pela teoria da bio-hidrogenação (Jenkins, 1993).

Lipídeos de rápida disponibilidade ruminal, como óleos vegetais livres ou sementes de oleaginosas processadas, aumentam a disponibilidade imediata de lipídeos insaturados no rúmen, reduzindo a capacidade de bio-hidrogenação pelos micro-organismos (Mohamed et al., 1988). Neste experimento, utilizou-se o óleo de soja, que possui liberação rápida, adicionado separadamente da dieta total e fornecido uma vez ao dia, que pode ter induzido queda na concentração de gordura do leite. Esse efeito ocorreu mesmo com a utilização de concentrações de lipídeos na dieta preconizadas pelo National... (2001), ou seja, abaixo de 5\% da matéria seca.

Para o teor de proteína do leite, observa-se que, no contraste LIPÍDEO, o óleo na presença de aminoácido provocou aumento de $0,14 \%$ $(\mathrm{p} \leq 0,05)$. Já na produção média de proteína do leite, no contraste LIPxAA, que compara o efeito do óleo de soja com o de lisina e metionina, a produção de proteína do leite apresentou aumento de $0,09 \mathrm{~kg} / \mathrm{dia}(\mathrm{p} \leq 0,10)$ (Tab. 3).

No presente estudo, a suplementação com lisina e metionina não resultou em elevação no teor de proteína do leite. Ocorreu aumento no teor de proteína quando se adicionou óleo na presença de lisina e metionina, independentemente da forma como esses foram adicionados na dieta $(\mathrm{p} \leq 0,05)$. Assim, observou-se que a utilização de aminoácidos complexados ou não ao óleo de soja promoveu aumento no percentual de proteína, o que sugere que pode ter havido deficiência em aminoácidos essenciais e que pode ter ocorrido proteção dos aminoácidos com a utilização de gordura, ou seja, a formação de um complexo protegido da degradação ruminal, sem, no entanto, afetar a produção de leite.

Os dados para consumo de matéria seca e cálculos de eficiência de utilização de matéria seca e de nitrogênio encontram-se na Tab. 4. A suplementação com lisina, metionina e óleo, independentemente da forma de fornecimento, não afetou o consumo dos animais. Os contrastes estimados também não diferiram para ingestão de matéria seca durante o período experimental (Tab. 4).

No experimento de Socha et al. (2005), a suplementação com lisina e metionina protegidas em dietas com 16 e 18,5\% de proteína bruta no início da lactação resultou em produção de $44,9 \mathrm{~kg}$ de leite/dia e consumo de $24,3 \mathrm{~kg} / \mathrm{dia}$ de matéria seca. Neste experimento, o consumo médio de matéria seca de vacas com produção diária de $32,1 \mathrm{~kg}$ de leite foi de $23,1 \mathrm{~kg}$ de matéria seca, sendo o valor predito pelo NRC (National..., 2001) de 22,7 kg/dia. Portanto, houve grande aproximação (98\%) do valor predito de consumo pelo NRC (National..., 2001).

Tabela 4: Efeito da suplementação de dietas de vacas com lisina e metionina associadas ou não com óleo de soja sobre a ingestão de matéria seca e a eficiência alimentar

\begin{tabular}{lccccccccc} 
& \multicolumn{4}{c}{ Dietas } & & \multicolumn{3}{c}{ Estimativas dos contrastes } \\
\cline { 2 - 3 } Variável & O+LM & OLM & OS & LM & & LIPÍDEO & AA & LIPxAA \\
\hline IMS $^{1}, \mathrm{~kg} /$ dia & 23,3 & 22,6 & 22,9 & 23,4 & 0,32 & $-0,45$ & 0,01 & $-0,46$ \\
PL/IMS & 1,37 & 1,40 & 1,38 & 1,41 & 0,03 & $-0,02$ & 0,01 & $-0,03$ \\
Nleite/Ncons. & 0,25 & 0,25 & 0,25 & 0,26 & 0,01 & $-0,01$ & 0,01 & $-0,02$ \\
\hline
\end{tabular}

${ }^{1}$ Cálculo da ingestão de matéria seca baseado na matéria seca a $65^{0} \mathrm{C}$.

$\mathrm{O}+\mathrm{LM}=$ controle; $\mathrm{OLM}=$ aminoácidos complexados com óleo; $\mathrm{OS}=$ óleo de soja; $\mathrm{LM}=$ lisina e metionina. LIPÍDEO $=\left(\mathrm{X}^{\mathrm{O}+\mathrm{LM}}+\mathrm{X}^{\mathrm{OLM}}\right) / 2-\mathrm{X}^{\mathrm{LM}} ; \mathrm{AA}=\left(\mathrm{X}^{\mathrm{O}+\mathrm{LM}}+\mathrm{X}^{\mathrm{OLM}}\right) / 2-\mathrm{X}^{\mathrm{OS}} ; \mathrm{LIPxAA}=\mathrm{X}^{\mathrm{OS}}-\mathrm{X}^{\mathrm{LM}} ; \mathrm{EPM}=$ erro-padrão da média; IMS = ingestão de matéria seca; $\mathrm{PL}=$ produção de leite; $\mathrm{N}=$ nitrogênio.

$* \mathrm{p} \leq 0,10$ 
A eficiência de utilização da matéria seca não foi afetada pelas dietas experimentais. A eficiência alimentar similar entre as dietas se deve à similaridade entre a produção de leite e o consumo de matéria seca.

A eficiência alimentar, ou eficiência de utilização da matéria seca, refere-se à capacidade da vaca em transformar o alimento consumido em leite. Neste trabalho, as vacas produziram, em média, $1,39 \mathrm{~kg}$ de leite para cada quilo de matéria seca consumida. Na meta-análise de Huhtanen e Hristov (2009), os valores médios para eficiência alimentar relatados nos EUA e na Europa foram, respectivamente, 1,30 e 1,45kg de leite/kg de matéria seca ingerida. As médias de produção de leite dos animais considerados para obtenção dos dados americanos e europeus foram de $31,0 \mathrm{~kg} / \mathrm{dia}$ e $25,4 \mathrm{~kg} / \mathrm{dia}$, respectivamente. Broderick (2003), ao trabalhar com vacas Holandesas primíparas e multíparas com média de produção de leite de 34,0 e $44,0 \mathrm{~kg} / \mathrm{dia}$, respectivamente, e com dietas com $16,7 \%$ e $18,4 \%$ de proteína bruta, encontrou valores médios de eficiência alimentar de 1,55 para dieta com $16,7 \%$ de proteína bruta e 1,51 para dieta com $18,4 \%$ de proteína bruta. A eficiência alimentar reduziu quando o teor proteico da dieta aumentou $(\mathrm{p} \leq 0,05)$.

A eficiência de utilização do nitrogênio refere-se à capacidade de secretar proteína no leite a partir do nitrogênio consumido na dieta. No estudo de Huhtanen e Hristov (2009), foi observado valor de eficiência de utilização do nitrogênio de 0,247 para as vacas com média de produção de $31,4 \mathrm{~kg}$ de leite/dia e teor proteico na dieta de $17,8 \%$; e eficiência de 0,277 para as vacas europeias com média de produção de $25,4 \mathrm{~kg}$ de leite/dia e teor proteico da dieta de $16,5 \%$. Estes autores demonstraram que a concentração de proteína bruta da dieta é o fator dietético mais importante sobre a eficiência de utilização do nitrogênio e que o aumento na produção de leite pode aumentar a eficiência de utilização do nitrogênio. Ainda, Broderick (2003), ao trabalhar com vacas Holandesas primíparas e multíparas com média de produção de leite de 34,0 e $44,0 \mathrm{~kg} / \mathrm{dia}$, respectivamente, e dieta com teor proteico de $16,7 \%$ e $18,4 \%$, encontrou valor para eficiência de utilização de nitrogênio de 0,270 e 0,239, respectivamente. Ou seja, ao aumentar o teor de proteína bruta da dieta, reduziu-se a eficiência de utilização de nitrogênio.

Socha et al. (2008) avaliaram a eficiência de utilização de nitrogênio em vacas suplementadas com metionina em três diferentes fases da lactação. No pico da lactação, vacas com produção de $40,0 \mathrm{~kg}$ de leite e $18,8 \%$ de $\mathrm{PB}$ na dieta; no início da lactação com produção de $38,2 \mathrm{~kg}$ de leite e $17,6 \% \mathrm{~PB}$; e no meio da lactação com produção de $34,5 \mathrm{~kg}$ de leite e 16,2\% PB apresentaram eficiência de utilização do nitrogênio de 0,$31 ; 0,28$ e 0,29 , respectivamente.

No presente estudo, para vacas com produção média de $32,1 \mathrm{~kg}$ de leite/dia no início do experimento e $17,4 \%$ de proteína bruta na dieta, o valor médio de eficiência de utilização do nitrogênio encontrado foi 0,25 (Tab. 4). A eficiência de utilização de nitrogênio poderia ser aumentada, segundo Broderick (2003), se o teor da PB da dieta fosse reduzido.

A otimização do balanço do total de aminoácidos na proteína metabolizável é fundamental para maximizar o desempenho da lactação com o mínimo de proteína na dieta. Isso possibilitará a redução da eliminação de nitrogênio urinário por unidade de leite produzido, bem como a economia de energia metabólica para a produção de leite ou outras funções do corpo (Socha et al., 2008).

\section{CONCLUSÃO}

A associação do óleo com lisina e metionina, a fim de obter proteção desses aminoácidos, não se justifica quando se busca aumento na produção de leite, mas pode ser justificada quando existir interesse no aumento do percentual de proteína do leite. No presente estudo, a produção de leite não foi afetada pela adição de lisina e metionina associadas ou não com óleo de soja; já o percentual de proteína aumentou $0,14 \%(\mathrm{p} \leq 0,05)$ com a adição de óleo na presença de lisina e metionina na dieta. A utilização do óleo de soja associado a aminoácidos para protegê-los da degradação ruminal pode ter sido eficiente no presente estudo, já que, independentemente da forma de associação da lisina, da metionina e do óleo, os efeitos sobre a produção de leite e o percentual de proteína do leite foram os mesmos. 


\section{REFERÊNCIAS}

ASSOCIATION of Official Analytical Chemists. Official Methods of Analysis of the Association of Official Analytical Chemists. 16. ed. AOAC, Washington, D.C., 1997.

BRODERICK, G.A. Effects of varying dietary protein and energy levels on the production of lactating dairy cows. J. Dairy Sci., v.86, p.13701381, 2003.

BRODERICK, G.A; STEVENSON, M.J.; PATTON, R.A. et al. Effects of supplementing rúmenprotected methionine on production and nitrogen excretion in lactating dairy cows. J. Dairy Sci., v.91, p.1092-1102, 2008.

GRAVERT, H.O. Breeding of dairy cattle. In: Dairy cattle production. New York: Elsevier Science, 1987. p.35-76.

HUHTANEN, P.; HRISTOV, A.N. A metaanalysis of the effects of dietary protein concentration and degradability on milk protein yield and milk $\mathrm{N}$ efficiency in dairy cows. $J$. Dairy Sci., v.92, p.3222-3232, 2009.

JENKINS, T.C. Lipid metabolism in the rúmen. J. Dairy Sci., v.76, p.3851-3863, 1993.

JENKINS, T.C.; FATOUHI, N. Effects of lecithin and corn oil on site of digestion, ruminal fermentation and microbial protein synthesis in sheep. J. Anim. Sci., v.68, p.460-466, 1990.

KAMALAK, A.; CANBOLAT, O.; GÜRBÜZ, Y., ÖZAY, O. Protected protein and amino acids ruminant nutrition. J. Sci. and Eng., v.8, p.84-88, 2005.

LAPIERRE, H.; PACHECO, D.; BERTHIAUME, R. et al. What is the supply of amino acids for a dairy cow? J. Dairy Sci., v.89, p.E1 - E14, 2006.

MOHAMED, O.E.; SATTER, L.D.; GRUMMER, R.R., EHLE, F.R. Influence of dietary cottonseed and soybean on milk production and composition. J. Dairy Sci., v.71, p.2677-2688, 1988.
NATIONAL Research Council (NRC). NUTRIENT Requeriments of Dairy Cattle. $7^{\text {th }}$ rev. Washington: Natl. Acad. Sci., 2001.

POLAN, C.E.; CUMMINS, K.A.; SNIFFEN, C.J. et al. Responses of dairy cows to supplemental rúmen-protected forms of methionine and lysine. J. Dairy Sci., v.74, p.2997-3013, 1991

SCHWAB, C.G.; BOZAK, C.K.; WHITEHOUSE, N.L. Amino acid limitation and flow to duodenum at four stages of lactation. 1 . Sequence of lysine and metionine limitation. $J$. Dairy Sci., v.75, p.3486-3502, 1992.

SOCHA, M.T.; PUTNAM, D.E.; GARTHWAITE, B.D. et al. Improving intestinal amino acid suplly of pre- and postpartum dairy cows with rúmenprotected methionine and lysine. J. Dairy Sci., v.88, p.1113-1126, 2005.

SOCHA, M.T.; SCHWAB, C.G.; PUTNAM, D.E. et al. Extent of methionine limitation in peak-, early-, and mid-lactation dairy cows. $J$. Dairy Sci., v.91, p.1996-2010, 2008.

STATISTICAL Analysis System - SAS. SASSTAT. The SAS system for windows version 8.0. Nashville: SAS Institut, 1999. CD-ROM. 1999.

TYRREL, H.F.; REID, J.T. Prediction of the energy value of cow's milk. J. Dairy Sci., v.48, p.1215-1223, 1965.

VAN SOEST, P.J.; ROBERTSON, J.B.; LEWIS, B.A. Methods for dietary fiber, neutral detergent fiber, and nonstarch polysaccharides in relation to animal nutrition. J. Dairy Sci., v.74, p.35833597, 1991.

VIRTANEN, A.I. Milk production of cows on protein - free feed. J. Dairy Sci., v.153, p.16031614, 1966. 